\title{
Deformation of an experimental drainage network in oblique collision
}

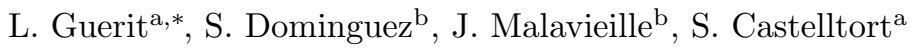 \\ ${ }^{a}$ University of Geneva, Department of Earth Sciences, Rue des Maraichers 13, 1205 Geneva, Switzerland \\ ${ }^{b}$ Université de Montpellier, Géosciences Montpellier UMR 5243, F-34095 Montpellier, France
}

\section{Abstract}

In oblique collision settings, parallel and perpendicular components of the relative plate motion can be partitioned into different structures of deformation and may be localized close to the plate boundary, or distributed on a wider region. In the Southern Alps of New Zealand, it has been proposed that one-third of the regional convergence is distributed in a broad area along the Southern Alps orogenic wedge. To better document and understand the regional dynamics of such systems, reliable markers of the horizontal tectonic motion over geological time scales are needed. River networks are able to record a large amount of distributed strain and they can thus be used to reconstruct the mode and rate of distribution away from major active structures. To explore the controls on river resilience to deformation, we develop an experimental model to investigate river pattern evolution over a doubly-vergent orogenic wedge growing in a context of oblique convergence. We use a rainfall system to activate erosion, sediment transport and river development on the model surface. At the end of the experiment, the drainage network is statistically rotated clockwise, confirming that rivers can record the distribution of motion along the wedge. Image analysis of channel time-space evolution shows how the fault-parallel and fault-perpendicular components of motion decrease toward the fault and impose rotation to the main trunk valleys. However, rivers do not record the whole imposed rotation rate, which suggest that the natural lateral channel dynamics can alter the capacity of rivers to act as passive markers of deformation.

\section{Introduction}

Fault-offset rivers have been widely used as passive markers to quantify horizontal tectonic motions displacements on largescale intracontinental strike-slip faults (Allen, 1965; Replumaz et al., 2001; Walker and Jackson, 2002; Hubert-Ferrari et al., 2002; Hollingsworth et al., 2008; Hubert-Ferrari et al., 2009; Klinger et al., 2011; Li et al., 2012). However, the use of active rivers and river networks to quantify the amount of deformation distributed away from localized tectonic structures is not straightforward. In fact, active geomorphic processes such as lateral erosion and river captures (Bishop, 1995; Brookfield, 1998; Hallet and Molnar, 2001; Clark et al., 2004) demonstrate clearly that drainage networks are dynamic entities organizing and reorganizing themselves

*Corresponding author 
when submitted to external forcings such as tectonic deformation (Brocard et al., 2003; Clark et al., 2004; Brocard et al., 2012; Babault et al., 2012; Willett et al., 2014; Lavé, 2015; Ferrater et al., 2015) and climate change (Tucker and Slingerland, 1997; Roe et al., 2003; Bonnet, 2009; Attal, 2009; Giachetta et al., 2014; Yang et al., 2016). Recently, several studies have proposed that river networks may in some cases act as faithful markers of large-scale surface horizontal displacements. Hallet and Molnar (2001) document for instance the distortion of several major rivers in the eastern Himalayan syntaxis in response to the indentation of India into Asia, thus suggesting that these rivers have acted as passive markers of the large scale distributed deformation in this area. Similarly, Ramsey et al. (2007) in Taiwan and Castelltort et al. (2012) in the Southern Alps of New Zealand (Figure 1) observe that rivers draining the orogen are deviated in a systematic pattern from the normal perpendicular drainage orientation classically observed in linear mountain ranges (Hovius, 1996; Castelltort and Simpson, 2006; Perron et al., 2008). Castelltort et al. (2012) propose that this orientation results from progressive shearing of initially transverse rivers that are thus suggested to act as passive markers of the deformation field. Yet, these authors remark that interfluves and a significant area of the drainage network of the Southern Alps encompass some degree of river capture and reorganization. Such dynamic behavior of drainage networks in response to tectonic deformation is illustrated by Yang et al. (2015). These authors used the $\chi$ metric and numerical experiments to demonstrate that the drainage pattern studied by Hallet and Molnar (2001) has been disrupted to some extent, leaving the major streams actively incising in the landscape and acting like passive markers of deformation, while interfluves are left as isolated remnants starved of drainage area, unable to balance tectonic uplift. Recently, Goren et al. (2015) document another example of large-scale distributed crustal deformation that is recorded in the arrangement of transverse rivers draining Mount Lebanon.

The fundamental problem outlined by these studies is the extent to which a drainage network is able to deform under a given tectonic strain field, and to retain a record of that deformation until it yields and loses memory (Kirby, 2012). This problem is crucial because it determines our ability to use river patterns to understand the partitioning of deformation at the Earth's surface between narrow zones of localized deformation and broad areas of distributed strain (Molnar et al., 1999; Hallet and Molnar, 2001; Ramsey et al., 2007; Castelltort et al., 2012). To complement the field observations and the numerical approaches undertaken in the studies cited above, we developed laboratory geomorphic experiments including tectonic and surface processes (erosion, sedimentation) couplings to describe and understand the response of a drainage network to a large scale horizontal deformation. We chose an oblique collisional context in which deformation is expected to be partitioned (Braun and Beaumont, 1995; Burbidge and Braun, 1998; Martinez et al., 2002; Upton et al., 2003; Leever et al., 2011) and that can be discussed with reference to the deformed drainage network of the Southern Alps of New Zealand. This paper documents the development of 
the experimental orogenic wedge, with a particular focus on the deformation of the drainage network on its surface.

\section{Experimental approach}

\subsection{General boundary conditions inspired by the Southern Alps of New Zealand}

Our objective is to perform analogue experiments in oblique setting with strain partitioning as observed in the Southern Alps of New Zealand, in order to study the plausibility of river deformation in such context. Therefore, the experimental model geometry, rheology and kinematic boundary conditions were inspired by the Southern Alps of New Zealand, but the regional specificities of the range are not considered.

Orogenic wedge morphology corresponds to an asymmetric doubly-vergent wedge, with a short and steep retroside and a longer proside with a lower slope (Figure 2a) (Willett et al., 1993; Koons, 1994). The Alpine Fault, separating the upper Australian plate to the North-West from the lower Pacific plate to the South-East, is the main tectonic structure of the range (Figure 1a). This major oblique strike-slip fault has accommodated about $400 \mathrm{~km}$ of lateral offset since the Cenozoic, and slip presently at about $40 \mathrm{~mm} / \mathrm{y}$ with a convergence angle of $11^{\circ}$ (Molnar et al., 1999; Wallace et al., 2007; Cox and Sutherland, 2007; Castelltort et al., 2012; Norris and Toy, 2014). The strike-parallel motion is of 35-40 mm/y and the strike-perpendicular component amounts to 7-8 mm/y (Walcott, 1998; Sutherland, 1999; Castelltort et al., 2012; Norris and Toy, 2014). Several observations suggest that the current relative plate motion is not entirely accommodated by slip along the Alpine Fault. Molnar et al. (1999) first pointed out the discrepancy between paleogeography reconstructions and the actual offset of remarkable terranes, which suggests that part of the total strain has been distributed away from the main plate boundary. In addition, Norris and Cooper (2001) showed that the offsets of quaternary geomorphic markers on the Alpine Fault do not match with the expected offsets deduced from the current plate motion. Finally, Castelltort et al. (2012) showed that the large-scale long-term and short-term discrepancies are compatible with the deformation of transverse rivers on the Eastern flank of the range. These studies suggest that only two-third of the motion is actually localized on the Alpine Fault itself while the remaining motion is distributed across the Southern Alps (Norris and Cooper, 2001; Castelltort et al., 2012; Norris and Toy, 2014).

At crustal scale, the range consists of a 15-km-thick layer of greywackes overlying about $15 \mathrm{~km}$ of schists (Figure 2a)(Cox and Sutherland, 2007; Herman et al., 2009). These materials, in particular the top layer of sandstones and greywackes, are affected by reverse faults that accommodate the deformation with an oblique displacement (Cox and Sutherland, 2007; Herman et al., 2009; Norris and Toy, 2014). Except for the Alpine Fault, these structures appear limited in width and rarely exceed 25-30 km in length (Norris and Toy, 2014, and references herein). 
The present-day rainfall over the Southern Alps is strongly affected by the rain-shadow effect which stops the precipitations brought by the Westerlies. Rainfall decreases from $\sim 12 \mathrm{~m} / \mathrm{y}$ on the west side of the range to less than $1 \mathrm{~m} / \mathrm{y}$ on the east side (Griffiths and McSaveney, 1983). This asymmetric rainfall pattern is believed to influence the general exhumation pattern of the range as erosion rates correlate strongly with the precipitations, being maximal on the west flank (Adams, 1980; Hicks et al., 1996; Cox and Sutherland, 2007).

\subsection{Setup and experimental run}

The experiment presented in this paper was performed in the Géosciences Montpellier laboratory. We used a table of 2.6 x $1.4 \mathrm{~m}$ covered by a carbon-kevlar film pulled by a computerized stepping motor on one side of the table (Graveleau et al., 2015). The motion of the film, which corresponds to the shortening rate of the experiment, is set to $7.5 \mathrm{~cm} / \mathrm{h}$. A rigid aluminum frame positioned at $\sim 30^{\circ}$ with respect to the motion direction and with a dip angle of $60^{\circ}$ imposes a velocity discontinuity that controls the development of the wedge (Figure $2 \mathrm{~b}$ and $2 \mathrm{c}$ ). The analogue material is loaded on the film, moved toward the oblique backstop and undergoes compression. The maximum shortening is limited by the size and the geometry of the setup, i.e., $\sim 80 \mathrm{~cm}$ in the present configuration. A doubly-vergent accretionary wedge develops in-sequence by the progressive propagation of frontal thrusts. Due to the cross-sectional geometry, with a horizontal basal décollement and a steep backstop, the wedge develops asymmetrically with a long and gentle slope at the proside and a short and steep slope at the retroside (Willett et al., 1993; Martinez et al., 2002) (Figure 2c). The main parameters and geometry of the experiment are summarized in Table 1.

Sprinklers above the deformation table generate rainfall in the form of micro-droplets of water. This rainfall system induces water run-off on the model surface which produces erosion, sediment transport and deposition such that a drainage network progressively develops on the sides of the wedge. Precipitations were made intermittent to enhance erosion over the model surface (12 s wet for $8 \mathrm{~s}$ dry). In order to simulate the effect of the precipitation gradient observed between the western and eastern sides of New Zealand (Griffiths and McSaveney, 1983), the sprinklers are placed such that mean rainfall rate decreases from 50 $\mathrm{mm} / \mathrm{h}$ at the northern edge of the model to a few $\mathrm{mm} / \mathrm{h}$ at its southern edge.

\subsection{Analogue materials}

To reproduce the first-order rheological layering of the Southern Alps crust (Cox and Sutherland, 2007; Herman et al., 2009), we designed a two-layer model. We used a granular mix, the MatIV, to model the brittle behavior of the upper-crustal layer and the evolution of surface morphology (see Graveleau et al., 2011, for the complete description of the MatIV properties). This granular mix is composed of $46 \%$ of glass beads with a median diameter of 100 to $200 \mu \mathrm{m}, 24 \%$ of PVC and $30 \%$ of silica powder and was specifically developed to model the interactions between deformation, erosion and sedimentation (Graveleau et al., 2011, 
2015). A few percent of graphite $(\sim 1 \%)$ is added to MatIV to improve syntectonic sediment bedding contrast and the accuracy of model surface kinematics measurements (see the Measurements subsection). However, MatIV is brittle, it deforms by faults and is therefore not suitable to simulate the behavior of the middle-lower crust, where deformation is neither purely brittle or ductile. This lower layer must be less resistant mechanically than MatIV in order to propagate strain but it must also be able to accommodate deformation by faults, and it must be erodible under the rainfall system when it reaches the surface along the backstop, on the retroside of the experimental wedge. We thus developed a new analogue material named hereafter MTK based on the MatIV composition, in which the silica powder is replaced by kaolinite and talcum, which presents a mechanical behavior close to clay (Table 2). Water is then added to the powder to obtain a paste that can be spread evenly on the experimental table. Water represents $20 \%$ of the final weight for MatIV and 25\% for MTK (Table 2). MTK exhibits less brittle mechanical behavior, as shown by its lower coefficient of internal friction (0.46) and cohesion (280 Pa) determined experimentally (Table 2, Figure 3a) using the procedure of Graveleau et al. (2011). Yet, this material erodes in the shape of incised valleys with steep hillslopes (Figure 3b).

The basal film is covered by a layer of glass beads to insure a low friction basal décollement simulating the intra-crustal décollement that allows the growth of the Southern Alps wedge. This taper layer is 1-cm thick close to the backstop, and its thickness decreases linearly to zero 60-cm further (not shown on Figure 2c). We then loaded the table with MTK to reach a thickness of $3 \mathrm{~cm}$ all over the table. At this point, we added a thin layer of glass beads $(\sim 1 \mathrm{~mm})$ to absorb the water seeping from MTK to the surface, to prevent any mixing between the two materials. This layer will also help to visualize the discontinuity between the materials in cross-sections. The upper layer is composed by $3 \mathrm{~cm}$ of MatIV. To better visualize deformation within this material, we added more graphite to the first centimeter, which will appear darker while preserving the same mechanical properties. The total thickness of the model is thus $6 \mathrm{~cm}$, which corresponds to the backstop height (Figure 2c). The surface of the model is flat at the beginning of the experiment.

\subsection{Measurements}

The evolution of the experiment is recorded by a $21 \mathrm{Mpx}$ Canon 5D mark II camera located above the model. It covers a field of view of $130 \mathrm{~cm} \times 70 \mathrm{~cm}$ with a resolution of $0.27 \mathrm{~mm} /$ pixel. Image acquisition is controlled by a computer and pictures are taken every 30 seconds. We use ENVI and GMT to perform sub-pixel image correlation of these pictures using a correlation window of $64 \times 32$ pixels to determine the incremental horizontal velocity field at each time step (between two pictures) over the whole wedge surface. The resulting velocity maps have an horizontal spatial resolution of $0.9 \mathrm{~mm}$ and an accuracy of about less than 50 microns. 
Laser interferometry is used to derive a digital elevation model (DEM) at different stages of model evolution (see Graveleau and Dominguez, 2008, for additional informations). During DEM acquisition, the model surface must be dry so the shortening and rainfall are paused between 45 minutes and one hour to dry the very first millimeters of the model surface. The laser interferogram is processed using SNAPHU software (Chen and Zebker, 2002) to unwrap the signal and obtain a regular topographic grid. The resulting DEMs have similar horizontal and vertical resolution of about $0.5 \mathrm{~mm}$. The duration of individual experiments is limited to 3 days because beyond this duration the behaviour of the material and the stability of the laser measurements both evolve. Given the maximum duration of experiments, the repeated 45-minutes pauses to acquire a full high-resolution DEM every $5 \mathrm{~cm}$ of shortening, and the length of the experimental apparatus, the optimal shortening rate that we can perform is 7.5 $\mathrm{cm} / \mathrm{h}$. Accordingly, each picture corresponds to an increment of $0.6 \mathrm{~mm}$ of shortening. At the end of the experiment, the model is left to dry for 3 to 4 days and then cut manually to obtain a 3D view of the internal structure of the wedge through serial cross sections.

The average position of the wedge front was extracted automatically from the velocity maps. The front position is defined as the position of the main velocity gradient and is then averaged over $2.5 \mathrm{~mm}$ of shortening (i.e., over four pictures). We use RiverTools to extract the drainage network from the DEMs and MATLAB to calculate the average orientation of the rivers. Main orientation corresponds to the weighted orthogonal least squares fit of a straight line to all the river pixels (Krystek and Anton, 2011). In addition to this quantitative analysis, some channels were mapped on pictures and their mean orientation was determined visually.

\section{Results}

In this section, we describe the evolution of the wedge and the drainage network during one experiment. These results were successfully reproduced in a second experiment but are not presented hereafter for the sake of brevity.

\subsection{Evolution of the wedge and drainage patterns through time}

The evolution of the wedge is illustrated by a series of consecutive pictures (Figure 4a-h) and associated DEMs (Figure 5). The main terms used to describe the wedge (divide, proside, retroside) and the spatial orientation of the model are shown on Figure 4i. In all experiments, gravitational slidings and collapses took place on the retroside, disturbing the evolution of the drainage pattern on this side of the orogen. To limit gravitational instability, future experiments shall be performed with larger erosion rates on the retroside in order, and to date, this part of the model has been excluded from the analyses. On the prowedge 
however, the lower slope inhibits gravitational processes and a large drainage network develops, similar to the one of the proside (South-East) in the Southern Alps of New Zealand.

At the beginning of the experiment, the surface is flat. After $2.5 \mathrm{~cm}$ of shortening, a first thrust named T1 emerges $\sim 10 \mathrm{~cm}$ southward of the velocity discontinuity, i.e., of the position of the backstop at depth (S point). This fault is composed by long segments $(\sim 9 \mathrm{~cm})$ trending nearly perpendicular to the shortening direction and by short segments $(\sim 3 \mathrm{~cm})$ running almost parallel to the shortening direction. It marks the active front of the wedge up to about $20 \mathrm{~cm}$ of total shortening. During this first stage, the wedge elevation increases and small streams start developing on its surface (Figures 4a, 4b, 5a and 5b). A second thrust T2 then reaches the surface on the west side on the model (Figures $4 \mathrm{c}$ and $5 \mathrm{c}$ ) before extending along the whole wedge (Figures $4 \mathrm{~d}$ and $5 \mathrm{~d}$ ). At this point, a network of transverse rivers seems to become permanent. After $\sim 50 \mathrm{~cm}$ of shortening, a third thrust T3 appears southward. At this stage, the prowedge is $25 \mathrm{~cm}$ in width on average (Figures $4 \mathrm{e}$ and $5 \mathrm{e}$ ), rivers lengthen and tend to flow toward the West (Figure 4f). After $20 \mathrm{~cm}$ of additional shortening (i.e., $70 \mathrm{~cm}$ of total shortening), a fourth thrust $\mathrm{T} 4$ develops and marks the new active wedge front (Figures $4 \mathrm{~g}$ and $5 \mathrm{~g}$ ). The prowedge is $40 \mathrm{~cm}$ in width and the maximum elevation is $12 \mathrm{~cm}$. During the 10 last $\mathrm{cm}$ of shortening, rivers continue to erode their banks, to transport and to deposit sediments downslope (Figures $4 \mathrm{~h}$ and $5 \mathrm{~h}$ ).

The width of the wedge is controlled by the emergence of these four successive thrusts at the front of the wedge. In consequence, the average width tends to grow step by step, by the sudden addition of increments of $\sim 10 \mathrm{~cm}$ in width (Figure 6). However, the position of the front is not fixed between two increments. On the contrary, it moves backwards toward the orogen, as highlighted by the red arrows on Figure 6. We interpret this retreat as related to the accommodation of continuous deformation such as folding on the hanging-wall, on the frontal thrust, and also to some underthrusting processes (Gutscher et al., 1996; Santimano et al., 2015).

The cross-sections obtained at the end of the experiment are presented on Figure 7 . The internal structure is equivalent along each section and is typical of accretionary wedges (Davis et al., 1983). Remnants of the first thrust T1 are found in the elevated part of the wedge close to the backstop (Figure 7). This thrust, which was probably continuous at first, is fragmented in several small faults, with an average dip of $10^{\circ}$. A few centimeters toward the front, a more continuous fault is observed which corresponds to the second main thrust T2. This fault can be split into two or three segments dipping at $25-30^{\circ}$. These two structures are affected by numerous, but small, secondary reverse faults which accommodated part of the shortening. The third thrust T3 dipping on average at $25^{\circ}$ is generally continuous from the base of the wedge up to the surface. The position of this fault is marked by the presence of well-preserved piggy-back basins. From these cross-sections, we can see that the last thrust 
T4 is a major fault which affected the material over its entire thickness, down to the basal décollement. The dip of this fault ranges between 20 and $30^{\circ}$. At the end of the experiment, the wedge thickness is close to twice the initial one in the thickest part of the wedge (Figure 7).

Finally, it is important to note that the rivers developing on the surface of the wedge are highly dynamic (Figure 4). Drainage basins are constantly evolving in response to fluvial erosion but also to the evolution of the topography. Sediments accumulate at the front of the wedge in a large system of alluvial fans and these sedimentary systems are eventually advected into the range. All along the experiment, rivers are abnormally oriented with their main flow direction primarily to the West (Figure 4). To analyze and quantify this observation, we extracted the drainage network and calculated the average orientation of the main rivers draining from the divide to the front of the wedge after $\sim 80 \mathrm{~cm}$ of shortening (Figure 8). This reveals that, at the end of the experiment, rivers are rotated clockwise by up to $35^{\circ}$ (River 6$)$.

\subsection{Horizontal velocity field across the wedge}

Sub-pixel image correlation measurements allows to obtain high-resolution velocity maps at the surface of the model. The horizontal velocity field is determined between two consecutive pictures, thus every $0.6 \mathrm{~mm}$ of shortening throughout the run. As an illustration, we here describe one example of the velocity field after $60 \mathrm{~cm}$ of shortening (Figure 9). The imposed shortening rate is $7.5 \mathrm{~cm} / \mathrm{h}$, corresponding to $1.25 \mathrm{~mm} / \mathrm{min}$.

The velocity field outside the wedge is quite homogeneous in the yet undeformed areas, with a magnitude of $1.25 \pm 0.06$ $\mathrm{mm} / \mathrm{min}$ and a mean orientation of $29.2 \pm 0.5^{\circ}$ with respect to the East-West (horizontal) axis of the figure. This is consistent with the imposed convergence angle and velocity, and the observed variations might result from the experimental conditions and analytical limitations. In our specific experimental setup, orientation and velocity are thus defined within a range of $5 \%$ and $10 \%$, respectively. The velocity abruptly changes after crossing the main frontal thrust. In fact, the amplitude of the velocity vector evolves from $1.2 \mathrm{~mm} / \mathrm{min}$ with orientation of 8 to $10^{\circ}$ with respect to the $\mathrm{EW}$ axis, to less than $0.8 \mathrm{~mm} / \mathrm{min}$ with orientation of $6^{\circ}$ at the backthrust fault (Figure 9). Northward of the main retro-fault, the velocity field falls to zero, as this area of the experiment is fixed.

The velocity component parallel to the main fault, i.e., to the velocity discontinuity along the backstop and named hereafter the fault-parallel component of the velocity, shows a clear evolution from South to North (in the figure reference frame, Figure 10a). The velocity is quite homogeneous in the undeformed area and is of $1.1 \pm 0.1 \mathrm{~mm} / \mathrm{min}$. This rate decreases northward between the front of the wedge and the divide, and velocity is typically around $0.8-1.0 \mathrm{~mm} / \mathrm{min}$, except in the most recent part of the wedge on the west side of the model, where high velocity is still observed. Finally, the velocity decreases from 0.6 to 0.8 
$\mathrm{mm} / \mathrm{min}$ between the divide and the main fault (i.e., across the retro-side of the wedge). A minor EW pattern can be observed and it could be related to material collapse at the edges of the experiment. Accordingly, the velocity field is deviated toward the East on this side. The velocity component perpendicular to the plate boundary, named hereafter the fault-perpendicular component, exhibits the same general pattern (Figure 10b). The velocity is quite homogeneous in the undeformed area of the model, with an average rate of $0.5 \pm 0.1 \mathrm{~mm} / \mathrm{min}$. Going northward, it decreases to 0.4 down to $0.2 \mathrm{~mm} / \mathrm{min}$ right after the front of the wedge and experiences a second fall to almost zero right after the former front of the wedge. Here again, we observe slightly higher velocity on the west side of the wedge, which corresponds to the most recent active part of the wedge. This velocity pattern implies that the horizontal compression is concentrated in the most frontal part of the wedge.

To summarize, the velocity observed at the surface of the wedge is a first order controlled by the frontal and the back thrusts, and it evolves strongly between the two structures. In addition, it seems to be partially structured by the main tectonic features.

\subsection{Deformation at the surface of the wedge}

The velocity field described in the previous section is a combination of pure shear and simple shear, resulting in a general rotation of the model's surface. For each velocity map, i.e., at each time increment, velocity was averaged in the longitudinal section in order to discuss the displacement imposed to the rivers as a function of time and distance to the backstop (Figure 11). Scatter between individual, short-term increments is quite large but they can be averaged over time to better describe the imposed velocity (Figure 11). It evolves across the wedge and in time, and so does the deformation imposed to any marker. In the following we only focus on the pro-wedge, where the main rivers develop.

The fault-parallel (EW) component of model surface displacements decreases from the front of the wedge to the divide, at any time during the experiment (Figure 11a). At first order, this component corresponds to a gradual decrease from the wedge front to about $10 \mathrm{~cm}$ southward of the S-point (Figure 11a). This point corresponds closely to the wedge divide, northward of which the EW velocity is quite constant (around $0.8 \mathrm{~mm} / \mathrm{min}$ ). The amount of distributed motion does not really change during the experiment as the velocity intensity changes from $1.1 \pm 0.1 \mathrm{~mm} / \mathrm{min}$ in the undeformed area (from the south edge of the model up to the wedge front) down to $0.8 \pm 0.1 \mathrm{~mm} / \mathrm{min}$ close to the divide (Figure 11a). However, as the length of the pro-wedge increases with time (Figures 6 and 11), the shear is distributed over an increasingly larger area. In consequence, the intensity of the deformation imposed by the EW horizontal velocity decreases through time. The fault-perpendicular (NS) velocity pattern is more complex as the convex shape suggested on Figure 10b is maintained during the whole experiment. Similar to the EW component, the amount of motion is quite stable through time and it evolves from $0.6 \pm 0.1 \mathrm{~mm} / \mathrm{min}$ in the deformed areas down to $0.2 \pm 0.2 \mathrm{~mm} / \mathrm{min}$ close to the divide, with a minimum of $0.1 \mathrm{~mm} / \mathrm{min}$ (Figure $11 \mathrm{~b}$ ). Here again, as the wedge widens in 
time, the fault-perpendicular shear is distributed over an increasingly larger area and the resulting deformation decreases as the experiment goes on. In addition to this first order pattern, this component appears segmented into a few steps (Figure 11b) in relation to the former frontal thrusts, now advected into the wedge. Finally, it appears that about $30 \%$ of the EW motion and $50 \%$ of the NS motion is distributed across the wedge.

The two components of the velocity field act together to deform any marker at the surface of the wedge. This deformation depends 1) on the maturity of the system and 2) on the orientation of the initial marker, and based on the average velocity field, it is possible to model the deformation of a passive marker within the wedge. A straight line, with a given initial orientation with respect to the North, is virtually placed on the surface of the wedge and at each step, this line is moved according to the displacement it experiences. It is then prolongated up to the front of the wedge, with the same initial orientation. Figures 12a, $12 \mathrm{~b}$ and $12 \mathrm{c}$ present the example of a marker with different initial orientation $\left(0^{\circ}, 20^{\circ}\right.$ and $40^{\circ}$, respectively) that would live for the whole experiment. The peculiar behavior of the retro-wedge (between 0 and $\sim 10 \mathrm{~cm}$ ) has a clear signature in the final morphology of the marker, but focusing on the pro-side only (i.e., from $\sim 10 \mathrm{~cm}$ southward of the backstop to the wedge front), the marker exhibits a general convex shape. However, working on a limited fraction of the marker, it is possible to define linear segments, and thus, a principal orientation. Deformation can thus be modeled for any initial angle, for any initiation time and for any duration, providing a framework to discuss the deformation pattern of the experimental drainage network.

\section{Discussion}

\subsection{Influence of the experimental conditions}

Classical analogue modelling approaches dedicated to the study of accretionary wedge evolution in oblique convergence setting have been already performed using dry sand (e.g., Malavieille, 1984; Burbidge and Braun, 1998; Dominguez et al., 1998; Martinez et al., 2002; McClay et al., 2004; Leever et al., 2011). In Martinez et al. (2002) and McClay et al. (2004), convergence angle and total shortening were comparable to those used in our experiment but the impact of erosion on the wedge dynamics was not taken into account. Our study provides, then, the first physical experiments of oblique convergence in a rainfall facility including realistic erosion and material transfer processes. As typically observed in such a tectonic context, model morphology and structure evolve into an asymmetric doubly-vergent wedge. The axial zone of this wedge is associated with short (few centimeters) but numerous " en echelon " strike-slip features (Figures 4 and 5). The wedge grows by the accretion of thrust units running parallel or subparallel to the backstop. Yet, the slope observed in the experiments by Martinez et al. (2002) and McClay et al. (2004) is higher than the one we obtained (around $17^{\circ}$ and $10^{\circ}$, respectively). This can be due to our lower basal friction obtained using the carbon-kevlar film (Martinez et al., 2002; Konstantinovskaia and Malavieille, 2005), but this is also certainly 
related to the erosive processes that maintain a lower slope angle and prevent the slope failure processes observed by McClay et al. (2004). In addition, the transport and deposition of sediments during the experiment allows the formation of sedimentary features that cannot be observed in experiments without erosion, such as large alluvial fans, which will ultimately be advected into the wedge as piggy-back basins (Figures 4 and 8).

The angle of convergence influences the amount of slip partitioning, and thus the mode of deformation and the rate of wedge growth (Chemenda et al., 2000). With a lower convergence angle, more time will be required to form an equivalent relief because the shortening component of deformation will be reduced. This motivated our choice to use a convergence angle higher than what is observed in the Southern Alps $\left(30^{\circ}\right.$ and $11^{\circ}$, respectively). It also controls the capacity of drainage networks to develop as the wedge grows. A minimum slope and length is required for a stream to maintain, as shown on Figures 4 and 5 . In our experiment, the first streams draining from the divide to the front of the wedge appear for a prowedge around $20 \mathrm{~cm}$ long and for a slope of $\sim 15^{\circ}$. Therefore, it is likely that perennial rivers will not form if the convergence angle is too low and the minimal angle has to be tested in our experimental setup. At low angle, a mountain range-like topography forms but is very narrow (McClay et al., 2004; Leever et al., 2011) which is not suitable for a drainage network to develop. Based on previous works in oblique collision but without erosion, a minimal angle of a dozen of degree might be required (McClay et al., 2004; Leever et al., 2011).

The backstop geometry is not expected to affect the degree of partitioning of the motion (Martinez et al., 2002). However, it can modify the localization of deformation and thus, its distribution across the wedge. Using a ramp rather than a simple point as a velocity discontinuity favors the localization of deformation right above the discontinuity and prevents the development of multiple retro-shear structures (Martinez et al., 2002; McClay et al., 2004; Leever et al., 2011). It might also favor a quite homogeneous velocity field at the surface of the wedge (Martinez et al., 2002). Finally, the geometry of the ramp can affect the position of the divide (Cruz et al., 2008). It is thus manifest that the capacity of the tectonic system to distribute deformation depends directly on its geometry, and therefore care must be taken in extending our results to other configurations.

\subsection{Relation with previous works}

Our study corroborates the results of Castelltort et al. (2012) showing that the rivers of the Southern Alps of New Zealand are deformed in response to a distributed shear across the relief. However, the geometry of the systems is not equivalent, leading to some important differences in the final morphology of the wedge and associated drainage system geometry.

The numerical setup in Castelltort et al. (2012) is very different from our, as it consists of a mature and symmetrical drainage entering an area of shear deformation. In this configuration, rivers experience increasing deformation as they are advected 
south-westward and a clear EW gradient of the river orientation can be observed (Figure 1b). In our experiment, rivers develop and deform simultaneously over the entire length of the orogenic wedge, such that there is no lateral gradient of deformation. In addition, we used a convergence angle of $30^{\circ}$, when it is only of $11^{\circ}$ in the numerical models and in the Southern Alps. This higher angle increases the compressive component, which is equal to $40 \%$ of the fault-parallel component in our experiment and to only $20 \%$ in numerical models and in the Southern Alps. In addition, a larger fraction of this component is distributed across the experimental wedge ( $\sim 50 \%$ vs $\sim 34 \%$ ). However, in the three settings, $\sim 30 \%$ of the motion parallel to the main fault is distributed across the relief.

The distribution of motion across the relief is also an important difference between our experiment and the work of Castelltort et al. (2012). In their study, both components of the velocity are imposed to decrease linearly from the southern to the northern edge of the model, whereas the velocity pattern that emerges in our experiments is less controlled and more variable since it is influenced by the structural evolution of the wedge (Figures 10 and 11). This is in better agreement with the natural case, as GPS data in the Southern Alps show that the orientation of the velocity vectors is not constant from the South-East to the North-West side of the range (Beavan and Haines, 2001). In addition, the ratio between the two components of the motion also evolves across the range, but contrary to what we observed, the fault-parallel component decreases faster than the faultperpendicular one (Beavan and Haines, 2001). It is beyond the scope of this study to discuss the influence of such differences in the final morphology of the rivers. It is likely that it will modify the amount of deformation recorded by rivers but it should not prevent rivers from recording deformation.

Finally, in each case, materials exhibit a Coulomb-like mechanical behavior and erosion is primarily limited to fluvial processes. However, the exact mechanisms and rates of erosion, transport and deposition inevitably differ between numerical models, laboratory experiments and natural settings (see Discussion in Graveleau et al., 2015). This can partly explain the larger valleys and more irregular drainage basins in our laboratory experiments compared with numerical simulations of Castelltort et al. (2012).

\subsection{Competition between the imposed rotation and the river dynamics}

Once the geometry of the experimental system is set, the shortening and the precipitation rates must be carefully chosen because these first-order parameters strongly control the wedge morphology and the deformation mechanisms. They must also be set so that passive deformation and river erosion can be expressed simultaneously in the landscape during the experiment. The precipitation rate must be high enough to keep pace with the relief growth but low enough to let the drainage network evolve in a steady state of equilibrium with tectonics. If precipitation rate is too high compared to shortening, it is very likely that 
rivers will be reset permanently and will not record the imposed deformation. The shortening rate must be moderate as shown by preliminary experiments indicating that high shortening rates induce such a rapid growth of the relief that gravitational processes (landslides) become a dominant erosion process shaping the morphology of the whole wedge. If shortening is too low, rivers do not deform and we expect a drainage network perpendicular to the main axis of the wedge independently of the initial imposed obliquity. More experiments must be carried out to explore the range of parameters leading to these extreme cases.

The experiment presented in this paper was designed to document an intermediate situation, in which both fluvial erosion and passive deformation are expressed in the landscape. The shortening rate was imposed by the experimental conditions and the precipitation rate was tuned to ensure the development of a drainage network but of a sufficient (i.e., visible in the landscape) deformation. As described above, rivers tend to rotate clockwise (Figure 8) and we interpret this rotation as a result of distributed shear across the wedge, as suggested in New Zealand and in Lebanon (Castelltort et al., 2012; Goren et al., 2015).

Our experiment was recorded by pictures taken at high frequency (every 30 seconds) and it is therefore possible to document accurately the evolution of a stream and its potential reorganization. Five channels were mapped on these pictures, their mean orientation was determined visually (Figure 13a), and then compared to the theoretical evolution of an equivalent passive marker, i.e., a marker that would appear at the same time, at the same position and with the same initial orientation (Figure 13b). The average orientation of each channel increases with time, in agreement with the trend expected for a passive marker, but the observed values differ from the theoretical one. Channels can be more clockwise-rotated than expected, or less rotated, and sometimes they can match the model (Figure 13b), demonstrating that rivers in this experiment do not behave like simple passive markers. It is difficult to propose a complete explanation of this behavior based on the present-day data set. It is probably linked to the fact that the drainage network is highly dynamic, with substantial erosion, deposition and network reorganization, and this fluvial activity can modify the average orientation of a stream.

\section{Conclusions}

We developed an experimental model of a doubly-vergent asymmetric wedge in oblique convergence setting including surface processes (erosion, sediment transport and deposition). Based on the quantitative analysis of model surface kinematics and drainage network geometric evolution, we show that in such tectonic context :

1. Model deformation is only partially accommodated on the main fault: $\sim 30 \%$ of the backstop-parallel and $\sim 50 \%$ of the backstop-perpendicular components of shortening are diffusively distributed across the wedge.

2. The backstop-parallel component of shortening decreases regularly from the front of the wedge to the divide. 
3. The backstop-perpendicular component of shortening is controlled by the main tectonics features i.e., by the former fronts advected into the wedge. This component mainly exists in the frontal area of the wedge and decreases to almost zero toward its inner part.

4. The total amount of shear does not change during the experiment but as the length of the pro-wedge increases though time, it is distributed over an increasingly larger area.

5. This pattern imposes a rotation to any surface marker, that can be predicted from the velocity field.

6. Consequently, the drainage network rotates with respect to the main axis of the range. However, accurate monitoring of channel evolution during the experiments documents their constant adjustment to deformation by erosional processes, and thus highlight the dynamic nature of rivers as markers of deformation.

These results confirm that rivers can record a large amount of distributed horizontal deformation, as suggested in New Zealand and in Lebanon (Castelltort et al., 2012; Goren et al., 2015). More experiments are however required to investigate further how river dynamics competes with surface deformation. This will allow to improve the theoretical framework necessary to interpret large-scale deformation of drainage networks in natural settings.

\section{Acknowledgements}

We are thankful to Patrice Rey and Karen Leever for their comments that strongly improve the quality of the paper. We thank C. Romano for his strong support for the design of the setup and during the experiments. This work was supported by the Swiss National Science Foundation project "Earth Surface Signaling Systems" (grant No 200021-146822).

\section{References}

Adams J. Contemporary uplift and erosion of the Southern Alps, New Zealand. Geological Society of America Bulletin 1980;91(1 Part II):1-114.

Allen C. Transcurrent faults in continental areas. Philosophical Transactions of the Royal Society of London A: Mathematical, Physical and Engineering Sciences 1965;258(1088):82-9.

Attal M. Geomorphology: Rivers split as mountains grow. Nature Geoscience 2009;2(11):747-8.

Babault J, Van Den Driessche J, Teixell A. Longitudinal to transverse drainage network evolution in the High Atlas (Morocco): The role of tectonics. Tectonics 2012;31(4). 
Beavan J, Haines J. Contemporary horizontal velocity and strain rate fields of the Pacific-Australian plate boundary zone through New Zealand. Journal of Geophysical Research: Solid Earth (1978-2012) 2001;106(B1):741-70.

Bishop P. Drainage rearrangement by river capture, beheading and diversion. Progress in Physical Geography 1995;19(4):449-73.

Bonnet S. Shrinking and splitting of drainage basins in orogenic landscapes from the migration of the main drainage divide. Nature Geoscience 2009;2(11):766-771.

Braun J, Beaumont C. Three-dimensional numerical experiments of strain partitioning at oblique plate boundaries: Implications for contrasting tectonic styles in the southern Coast Ranges, California, and central South Island, New Zealand. Journal of Geophysical Research: Solid Earth 1995;100(B9):18059-74.

Brocard G, Van Der Beek P, Bourlès D, Siame L, Mugnier JL. Long-term fluvial incision rates and postglacial river relaxation time in the French Western Alps from 10 Be dating of alluvial terraces with assessment of inheritance, soil development and wind ablation effects. Earth and Planetary Science Letters 2003;209(1):197-214.

Brocard G, Willenbring J, Suski B, Audra P, Authemayou C, Cosenza-Muralles B, Morán-Ical S, Demory F, Rochette P, Vennemann T, Holliger K, Teyssier C. Rate and processes of river network rearrangement during incipient faulting: The case of the Cahabón River, Guatemala. American Journal of Science 2012;312(5):449-507.

Brookfield M. The evolution of the great river systems of southern Asia during the Cenozoic India-Asia collision: rivers draining southwards. Geomorphology 1998;22(3):285-312.

Burbidge DR, Braun J. Analogue models of obliquely convergent continental plate boundaries. Journal of Geophysical Research: Solid Earth 1998;103(B7):15221-37.

Castelltort S, Goren L, Willett SD, Champagnac JD, Herman F, Braun J. River drainage patterns in the New Zealand Alps primarily controlled by plate tectonic strain. Nature Geoscience 2012;5(10):744-8.

Castelltort S, Simpson G. River spacing and drainage network growth in widening mountain ranges. Basin Research $2006 ; 18(3): 267-76$.

Chemenda A, Lallemand S, Bokun A. Strain partitioning and interplate friction in oblique subduction zones: constraints provided by experimental modeling. Journal of Geophysical Research: Solid Earth 2000;105(B3):5567-81.

Chen CW, Zebker HA. Phase unwrapping for large sar interferograms: statistical segmentation and generalized network models. Geoscience and Remote Sensing, IEEE Transactions on 2002;40(8):1709-19. 
Clark M, Schoenbohm L, Royden L, Whipple K, Burchfiel B, Zhang X, Tang W, Wang E, Chen L. Surface uplift, tectonics, and erosion of eastern Tibet from large-scale drainage patterns. Tectonics 2004;23(1):TC1006.

Cox SC, Sutherland R. Regional geological framework of South Island, New Zealand, and its significance for understanding the active plate boundary. A continental plate boundary: tectonics at South Island, New Zealand 2007;:19-46.

Cruz L, Teyssier C, Perg L, Take A, Fayon A. Deformation, exhumation, and topography of experimental doubly-vergent orogenic wedges subjected to asymmetric erosion. Journal of Structural Geology 2008;30(1):98-115.

Davis D, Suppe J, Dahlen F. Mechanics of fold-and-thrust belts and accretionary wedges. Journal of Geophysical Research 1983;88(B2):1153-72.

Dominguez S, Lallemand S, Malavieille J, Schnürle P. Oblique subduction of the Gagua Ridge beneath the Ryukyu accretionary wedge system: Insights from marine observations and sandbox experiments. Marine Geophysical Researches 1998;20(5):383402.

Ferrater M, Booth-Rea G, Pérez-Peña JV, Azañón JM, Giaconia F, Masana E. From extension to transpression: Quaternary reorganization of an extensional-related drainage network by the Alhama de Murcia strike-slip fault (eastern Betics). Tectonophysics 2015;

Giachetta E, Refice A, Capolongo D, Gasparini NM, Pazzaglia FJ. Orogen-scale drainage network evolution and response to erodibility changes: insights from numerical experiments. Earth Surface Processes and Landforms 2014;39(9):1259-68.

Goren L, Castelltort S, Klinger Y. Modes and rates of horizontal deformation from rotated river basins: Application to the Dead Sea fault system in Lebanon. Geology 2015;43(9):843-6.

Graveleau F, Dominguez S. Analogue modelling of the interaction between tectonics, erosion and sedimentation in foreland thrust belts. Comptes Rendus Geoscience 2008;340(5):324-33.

Graveleau F, Hurtrez JE, Dominguez S, Malavieille J. A new experimental material for modeling relief dynamics and interactions between tectonics and surface processes. Tectonophysics 2011;513(1):68-87.

Graveleau F, Strak V, Dominguez S, Malavieille J, Chatton M, Manighetti I, Petit C. Experimental modelling of tectonicserosion-sedimentation interactions in compressional, extensional, and strike-slip settings. Geomorphology 2015;244:146-68.

Griffiths GA, McSaveney M. Distribution of mean annual precipitation across some steepland regions of New Zealand. New Zealand journal of science 1983;26(2):197-209. 
Gutscher MA, Kukowski N, Malavieille J, Lallemand S. Cyclical behavior of thrust wedges: Insights from high basal friction sandbox experiments. Geology 1996;24(2):135-8.

Hallet B, Molnar P. Distorted drainage basins as markers of crustal strain east of the Himalaya. Journal of Geophysical Research: Solid Earth 2001;106(B7):13697-709.

Herman F, Cox SC, Kamp PJ. Low-temperature thermochronology and thermokinematic modeling of deformation, exhumation, and development of topography in the central Southern Alps, New Zealand. Tectonics 2009;28(5).

Hicks DM, Hill J, Shankar U. Variation of suspended sediment yields around New Zealand: the relative importance of rainfall and geology. IAHS publication 1996;:149-56.

Hollingsworth J, Jackson J, Walker R, Nazari H. Extrusion tectonics and subduction in the eastern South Caspian region since 10 Ma. Geology 2008;36(10):763-6.

Hovius N. Regular spacing of drainage outlets from linear mountain belts. Basin Research 1996;8:29-44.

Hubert-Ferrari A, Armijo R, King G, Meyer B, Barka A. Morphology, displacement, and slip rates along the North Anatolian Fault, Turkey. Journal of Geophysical Research: Solid Earth 2002;107(B10):ETG-9.

Hubert-Ferrari A, King G, van der Woerd J, Villa I, Altunel E, Armijo R. Long-term evolution of the North Anatolian Fault: new constraints from its eastern termination. Geological Society, London, Special Publications 2009;311(1):133-54.

Kirby E. Geomorphology: Tectonically twisted rivers. Nature Geoscience 2012;5(10):688-9.

Klinger Y, Etchebes M, Tapponnier P, Narteau C. Characteristic slip for five great earthquakes along the Fuyun fault in China. Nature Geoscience 2011;4(6):389-92.

Konstantinovskaia E, Malavieille J. Erosion and exhumation in accretionary orogens: Experimental and geological approaches. Geochemistry, Geophysics, Geosystems 2005;6(2).

Koons PO. Three-dimensional critical wedges: Tectonics and topography in oblique collisional orogens. Journal of Geophysical Research: Solid Earth 1994;99(B6):12301-15.

Krystek M, Anton M. A least-squares algorithm for fitting data points with mutually correlated coordinates to a straight line. Measurement Science and Technology 2011;22(3):035101.

Lavé J. Landscape inversion by stream piracy. Nature 2015;520(7548):442-4. 
Leever KA, Gabrielsen RH, Sokoutis D, Willingshofer E. The effect of convergence angle on the kinematic evolution of strain partitioning in transpressional brittle wedges: Insight from analog modeling and high-resolution digital image analysis. Tectonics $2011 ; 30(2)$

Li H, Van der Woerd J, Sun Z, Si J, Tapponnier P, Pan J, Liu D, Chevalier ML. Co-seismic and cumulative offsets of the recent earthquakes along the Karakax left-lateral strike-slip fault in western Tibet. Gondwana Research 2012;21(1):64-87.

Malavieille J. Modelisation experimentale des chevauchements imbriques; application aux chaines de montagnes. Bulletin de la Société géologique de France 1984;1:129-38.

Martinez A, Malavieille J, Lallemand S, Collot JY. Partition de la déformation dans un prisme d'accrétion sédimentaire en convergence oblique: approche expérimentale. Bulletin de la Societe Geologique de France 2002;173(1):17-24.

McClay K, Whitehouse P, Dooley T, Richards M. 3d evolution of fold and thrust belts formed by oblique convergence. Marine and Petroleum Geology 2004;21(7):857-77.

Molnar P, Anderson HJ, Audoine E, Eberhart-Phillips D, Gledhill KR, Klosko ER, McEvilly TV, Okaya D, Savage MK, Stern T, Wu F. Continuous deformation versus faulting through the continental lithosphere of New Zealand. Science 1999;286(5439):516-9.

Norris RJ, Cooper AF. Late Quaternary slip rates and slip partitioning on the Alpine Fault, New Zealand. Journal of Structural Geology 2001;23(2):507-20.

Norris RJ, Toy VG. Continental transforms: A view from the Alpine Fault. Journal of Structural Geology 2014;64:3-31.

Perron JT, Dietrich WE, Kirchner JW. Controls on the spacing of first-order valleys. Journal of Geophysical Research: Earth Surface $2008 ; 113(\mathrm{~F} 4)$.

Ramsey LA, Walker RT, Jackson J. Geomorphic constraints on the active tectonics of southern taiwan. Geophysical Journal International 2007;170(3):1357-72.

Replumaz A, Lacassin R, Tapponnier P, Leloup P. Large river offsets and Plio-Quaternary dextral slip rate on the Red River fault (Yunnan, China). Journal of Geophysical Research: Solid Earth 2001;106(B1):819-36.

Roe GH, Montgomery DR, Hallet B. Orographic precipitation and the relief of mountain ranges. Journal of Geophysical Research: Solid Earth 2003;108(B6). 
Santimano T, Rosenau M, Oncken O. Intrinsic versus extrinsic variability of analogue sand-box experiments-Insights from statistical analysis of repeated accretionary sand wedge experiments. Journal of Structural Geology 2015;75:80-100.

Sutherland R. Cenozoic bending of New Zealand basement terranes and Alpine Fault displacement: a brief review. New Zealand Journal of Geology and Geophysics 1999;42(2):295-301.

Tucker GE, Slingerland R. Drainage basin responses to climate change. Water Resources Research 1997;33(8):2031-47.

Upton P, Koons PO, Eberhart-Phillips D. Extension and partitioning in an oblique subduction zone, New Zealand: Constraints from three-dimensional numerical modeling. Tectonics 2003;22(6).

Walcott R. Modes of oblique compression: Late Cenozoic tectonics of the South Island of New Zealand. Reviews of Geophysics 1998;36(1):1-26.

Walker R, Jackson J. Offset and evolution of the Gowk fault, SE Iran: a major intra-continental strike-slip system. Journal of structural Geology 2002;24(11):1677-98.

Wallace LM, Beavan J, McCaffrey R, Berryman K, Denys P. Balancing the plate motion budget in the South Island, New Zealand using GPS, geological and seismological data. Geophysical Journal International 2007;168(1):332-52.

Willett S, Beaumont C, Fullsack P. Mechanical model for the tectonics of doubly vergent compressional orogens. Geology 1993;21(4):371-4.

Willett SD, McCoy SW, Perron JT, Goren L, Chen CY. Dynamic reorganization of river basins. Science 2014;343(6175):1248765.

Yang R, Fellin MG, Herman F, Willett SD, Wang W, Maden C. Spatial and temporal pattern of erosion in the Three Rivers Region, southeastern Tibet. Earth and Planetary Science Letters 2016;433:10-20.

Yang R, Willett SD, Goren L. In situ low-relief landscape formation as a result of river network disruption. Nature 2015;520(7548):526-9. 


\begin{tabular}{|c|c|}
\hline Model thickness & $6 \mathrm{~cm}$ \\
Precipitations & 0 to $50 \mathrm{~mm} / \mathrm{h}$ \\
Imposed motion & $7.5 \mathrm{~cm} / \mathrm{h}$ \\
Convergence angle & $30^{\circ}$ \\
Backstop dip & $60^{\circ}$ \\
Total shortening & $75 \mathrm{~cm}$ \\
\hline
\end{tabular}

Table 1: Main characteristics and boundary conditions of the experiment.

\begin{tabular}{ccccccccc}
\cline { 2 - 4 } & Glass beads & PVC & Silica Powder & Talcum & Kaolinite & Water & C & $\mu$ \\
\hline MatI & $37 \%$ & $19 \%$ & $24 \%$ & - & - & $20 \%$ & $750 \mathrm{~Pa}$ & 1.13 \\
MTK & $34 \%$ & $18 \%$ & - & $22 \%$ & $1 \%$ & $25 \%$ & $280 \mathrm{~Pa}$ & 0.46 \\
\hline
\end{tabular}

Table 2: Composition and characteristics of the two analogue materials used in the model (this study, Graveleau and Dominguez, 2008, and Graveleau et al., 2011). C is the cohesion and $\mu$ the coefficient of internal friction.

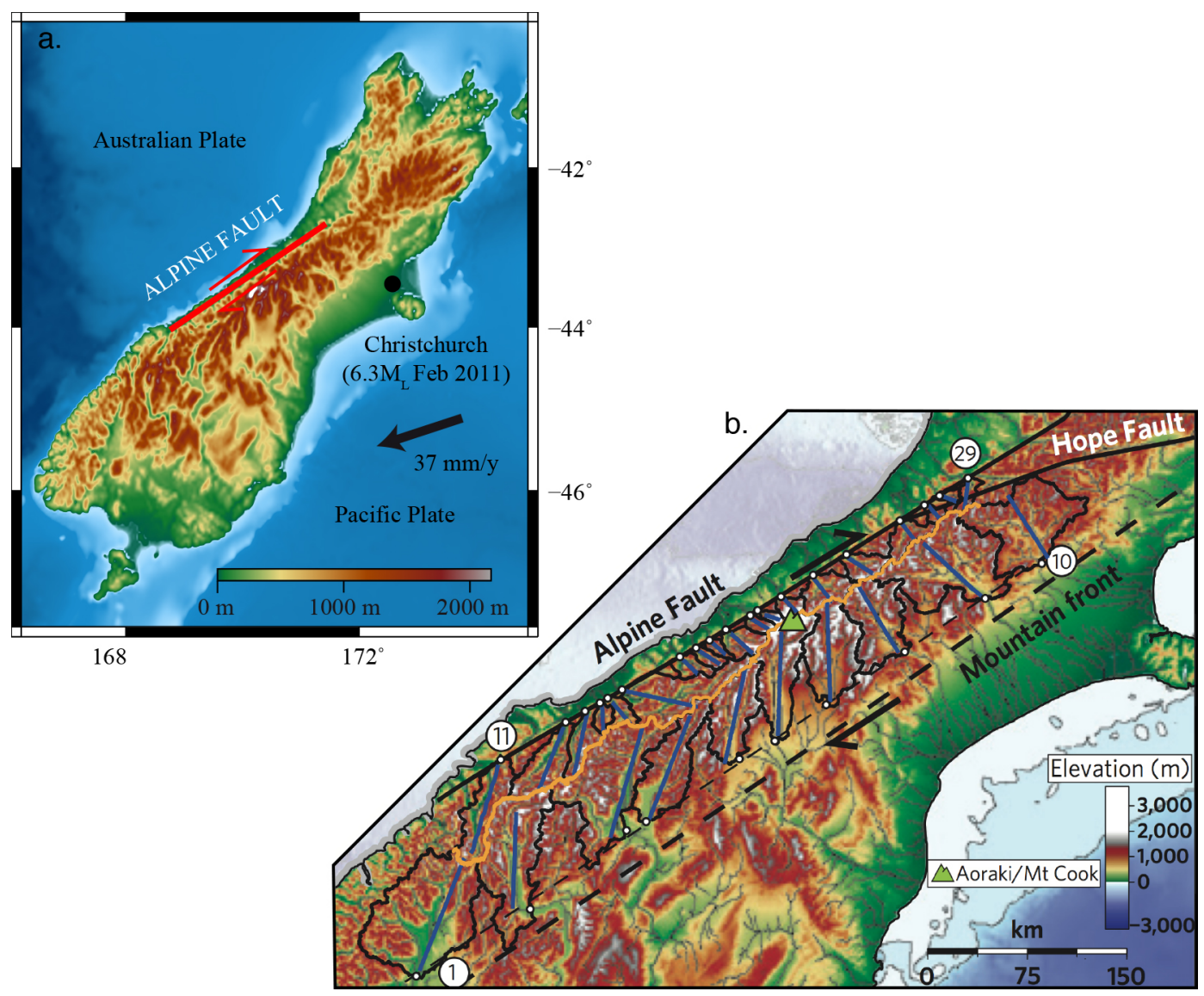

Figure 1: a) Simplified geodynamic context of the South Island of New Zealand. b) Topography of the South Island with major river basins (black), main river orientation (blue) and the main divide (orange) (modified from Castelltort et al., 2012). 


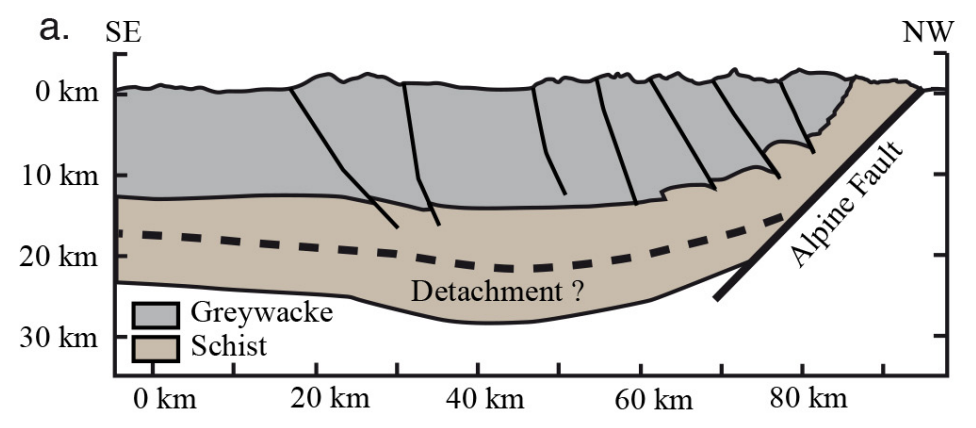

b.
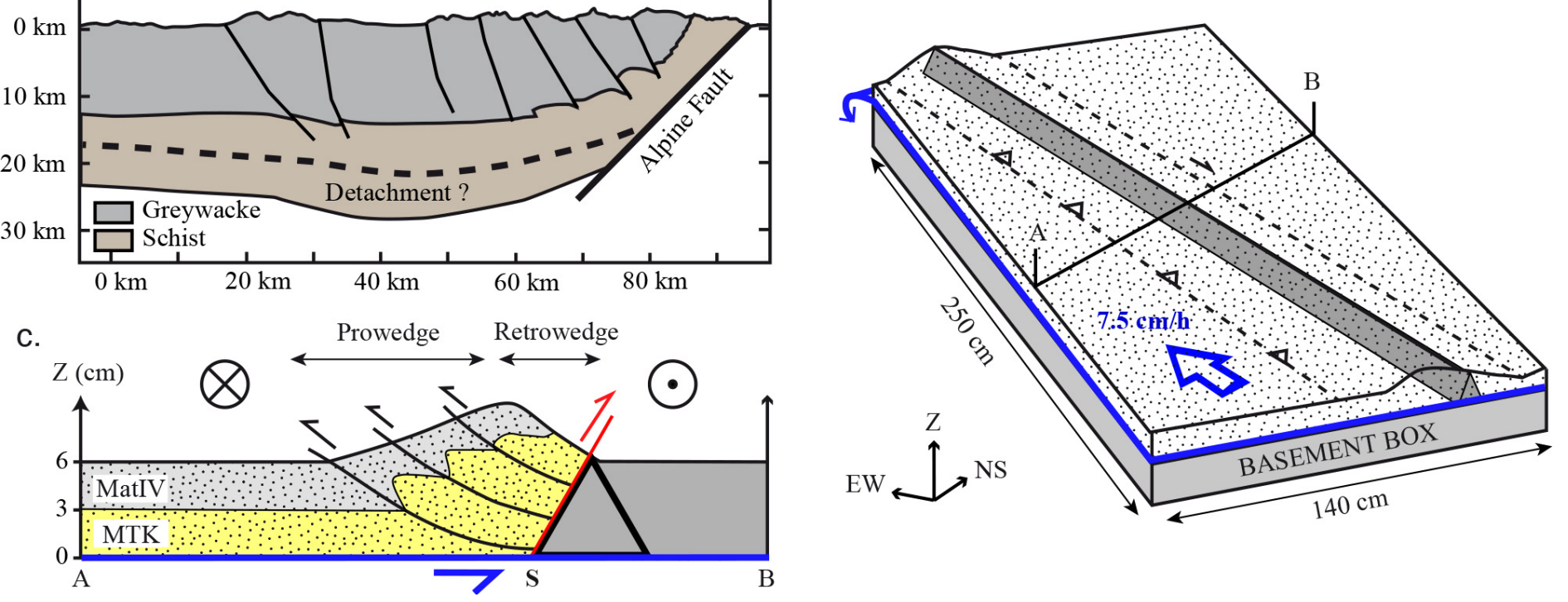

Figure 2: a) Simplified cross-section of the Southern Alps of New Zealand (modified from Herman et al., 2009). Experimental setup in b) side view and c) cross-section (see text for details about the materials). S indicates the velocity discontinuity. 

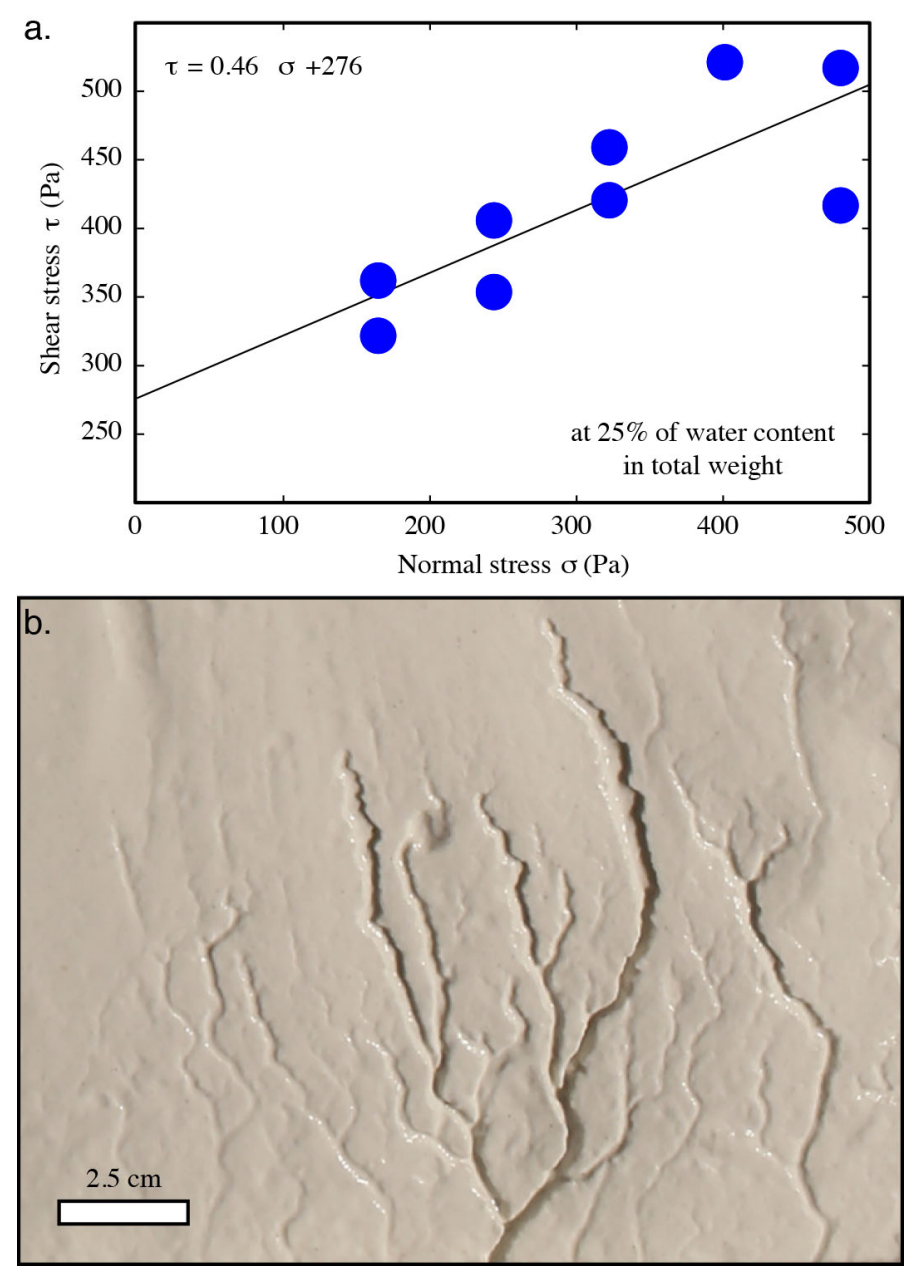

Figure 3: Properties of the analogue material used for the lower layer of the model (the MTK). a) Mohr-Coulomb failure envelop for the MTK. The best-fit slope and the intercept with y-axis define the coefficient of internal friction and the cohesion, respectively. b) Drainage network in MTK after 70 minutes of rain, for a slope of $20^{\circ}$. 

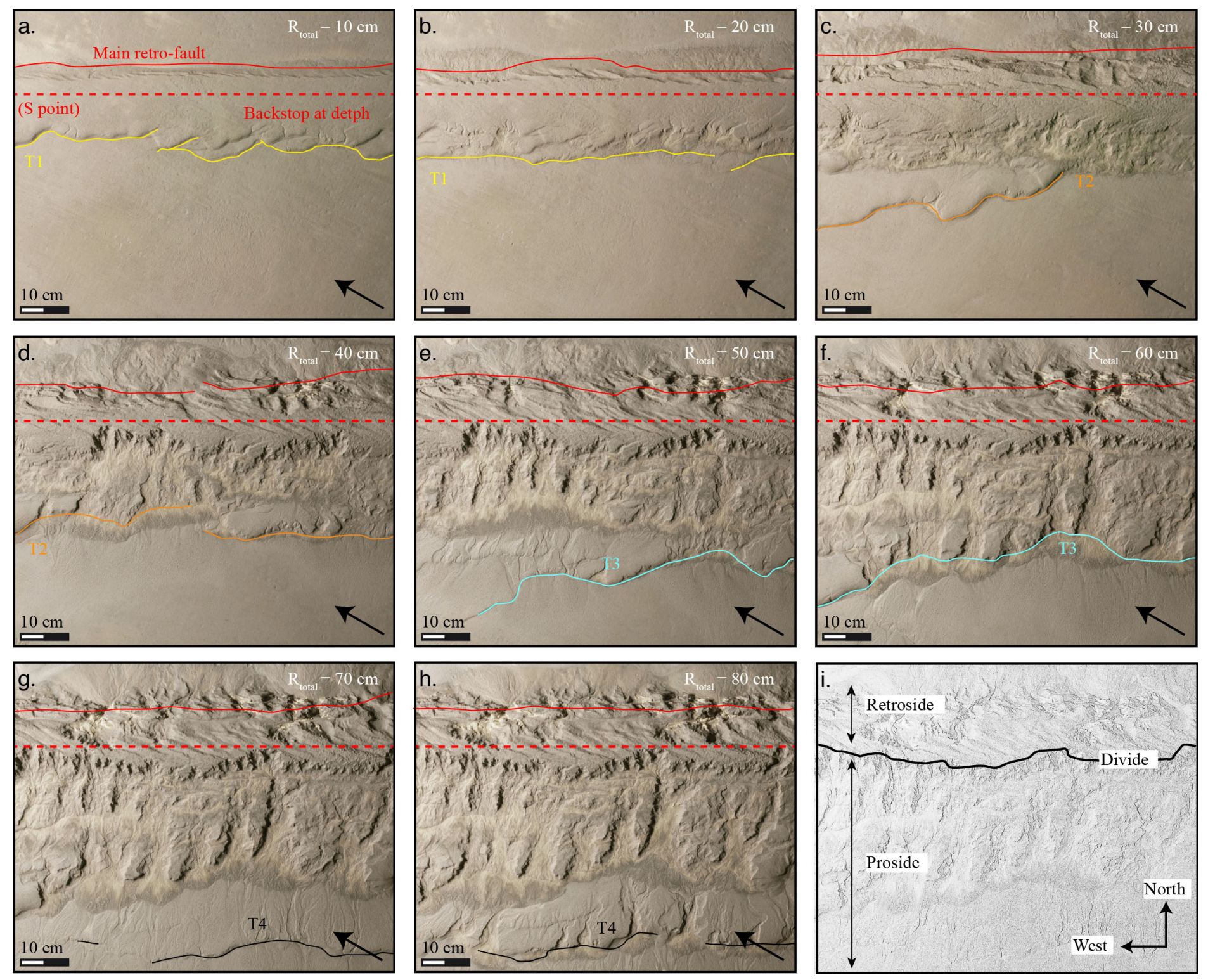

Figure 4: $\mathrm{a}-\mathrm{h}$ ) Evolution of the experimental wedge through time. Each picture corresponds to a shortening increment of $\sim 10 \mathrm{~cm}$. The main thrusts are labelled as they appear, from the first thrust ( $\mathrm{T} 1$, in yellow) to the last one ( $\mathrm{T} 4$, in black). The red dotted line indicates the position of the backstop at depth, i.e., of the velocity discontinuity (S point), the red line of the main retro-fault at the surface, the black arrow the direction of shortening. i) Definition of the divide (black line), pro- and retro-sides and spatial orientation. 

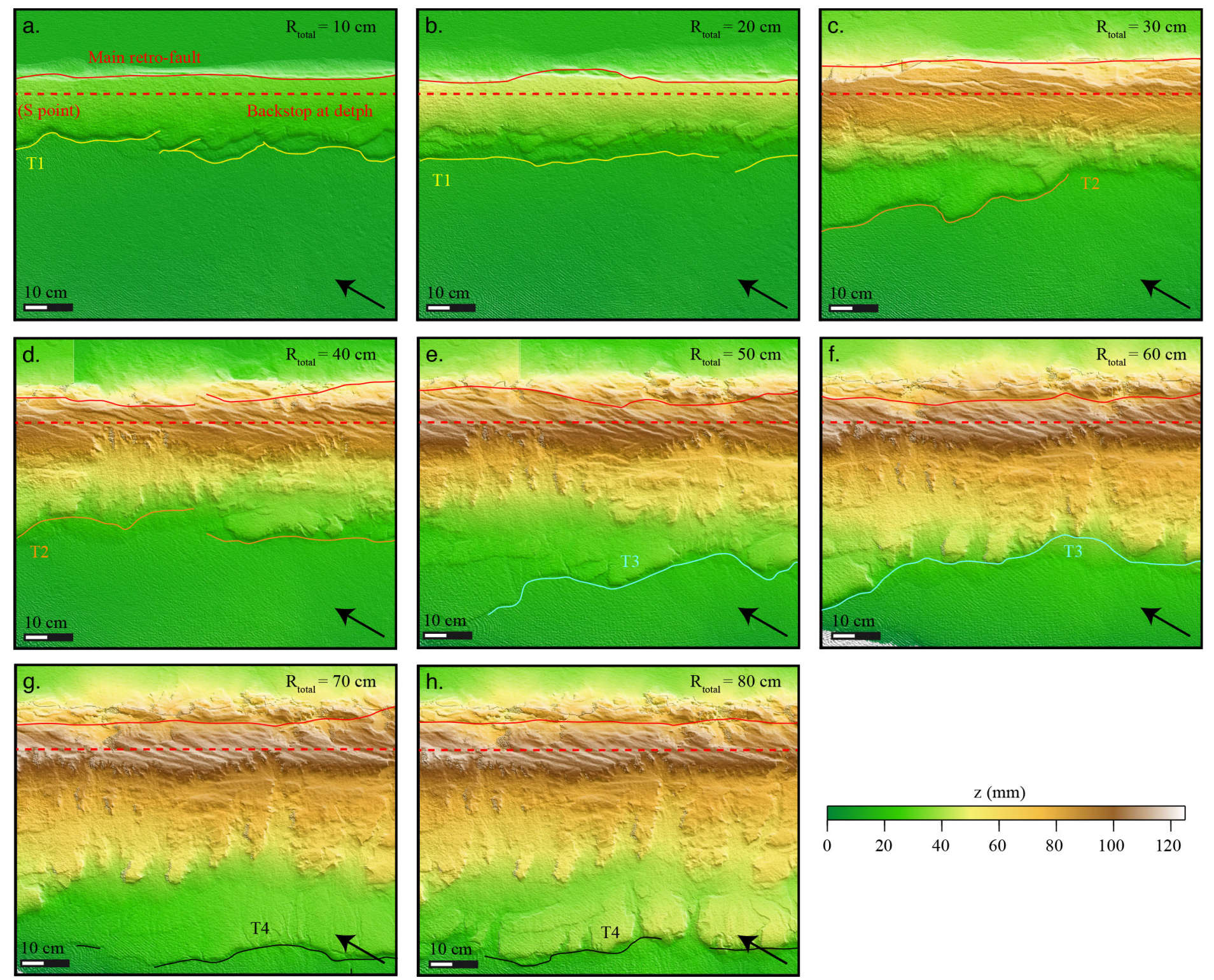

Figure 5: Evolution of the wedge morphology through time. Each DEM corresponds to a shortening increment of $\sim 10 \mathrm{~cm}$ and is associated to the equivalent label $(\mathrm{a}-\mathrm{h})$ of Figure 4. The main thrusts are labelled as they appear, from the first thrust (T1, in yellow) to the last one (T4, in black). The red dotted line indicates the position of the backstop at depth, i.e., of the velocity discontinuity (S point), the red line of the main retro-fault at the surface, the black arrow the direction of shortening. 


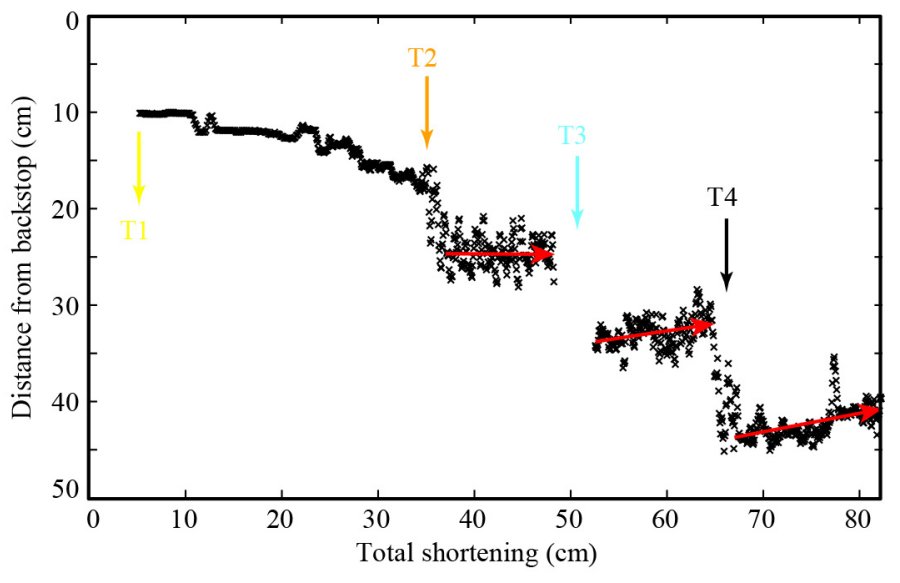

Figure 6: Average position of the wedge front though time (black crosses). The local front position is defined as the position of the main local velocity gradient and is then averaged in space, resulting in one average position for each picture. The emergence of the main thrusts (T1 to T4) are indicated, and the red arrows highlight the main trend. Distance is given from the position of the backstop at depth (S point).

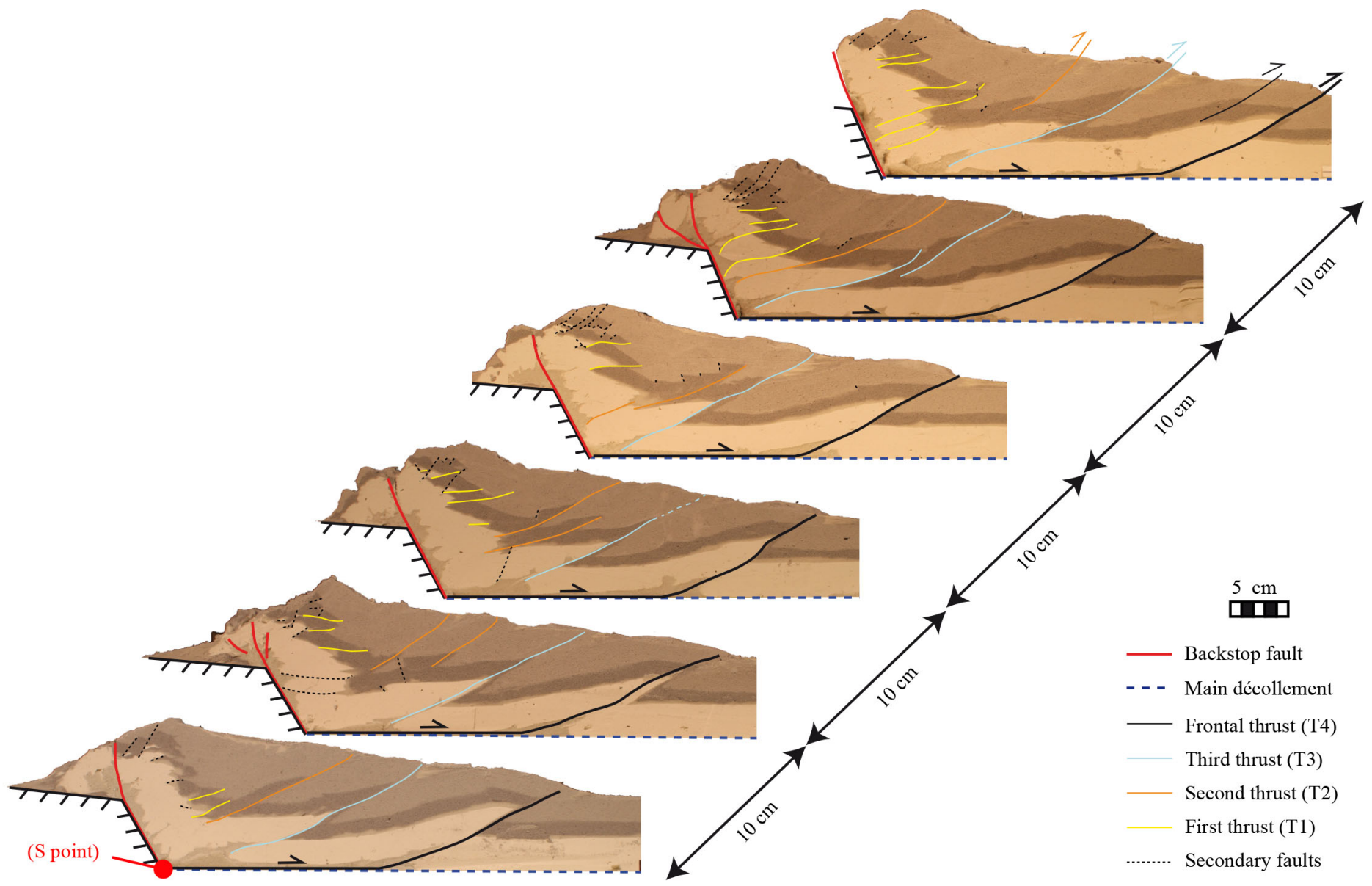

Figure 7: Cross-sections along the wedge at the end of the experiment. The main faults are mapped and are associated with the successive thrust T1 (yellow), T2 (orange), T3 (blue) and T4 (black). Small and secondary faults are also indicated (black dotted lines). 


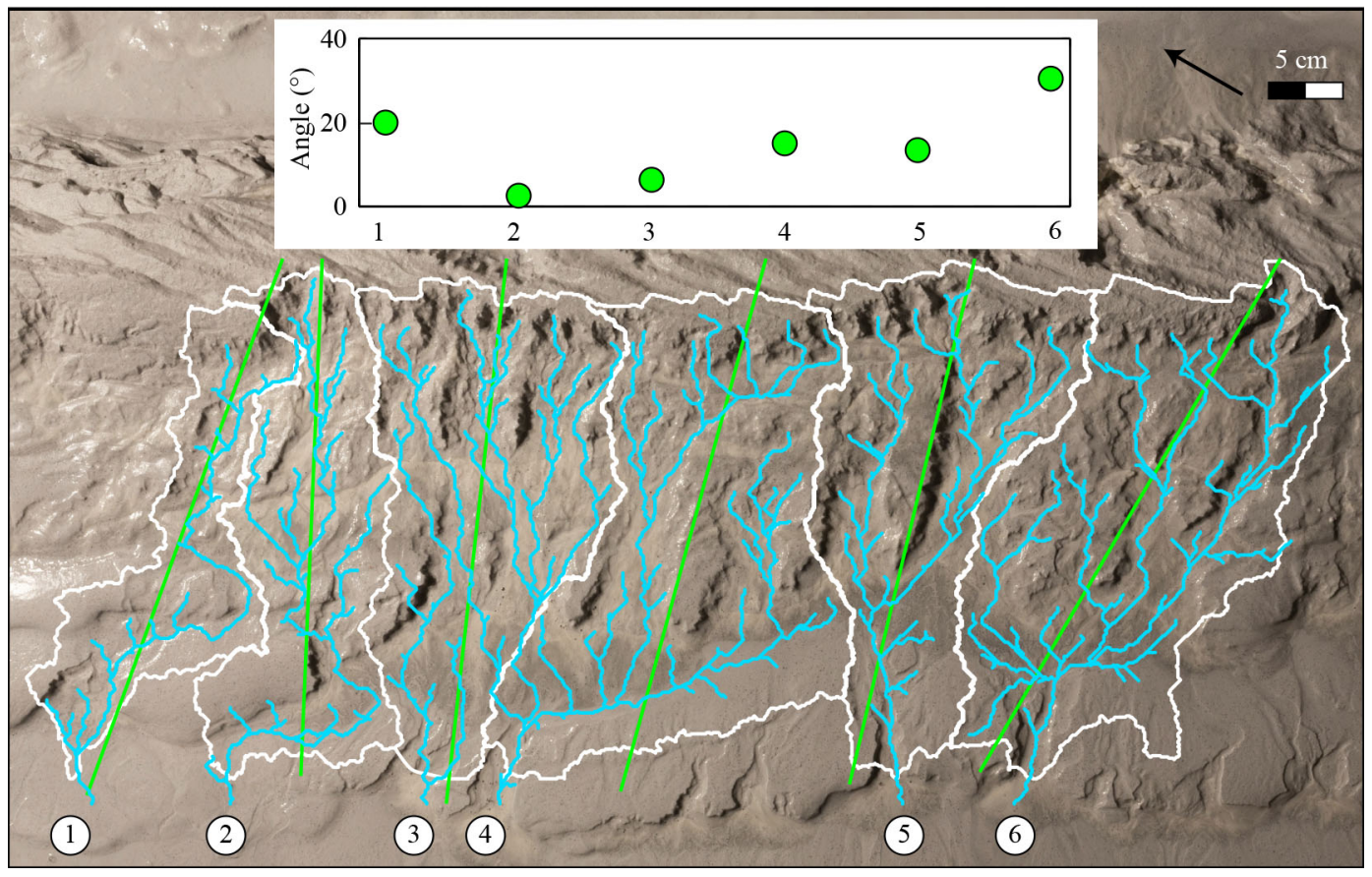

Figure 8: Orientation (green lines) of the main rivers (blue lines) after $\sim 80 \mathrm{~cm}$ of shortening. White lines define the drainage basins and the black arrow indicates the direction of shortening.

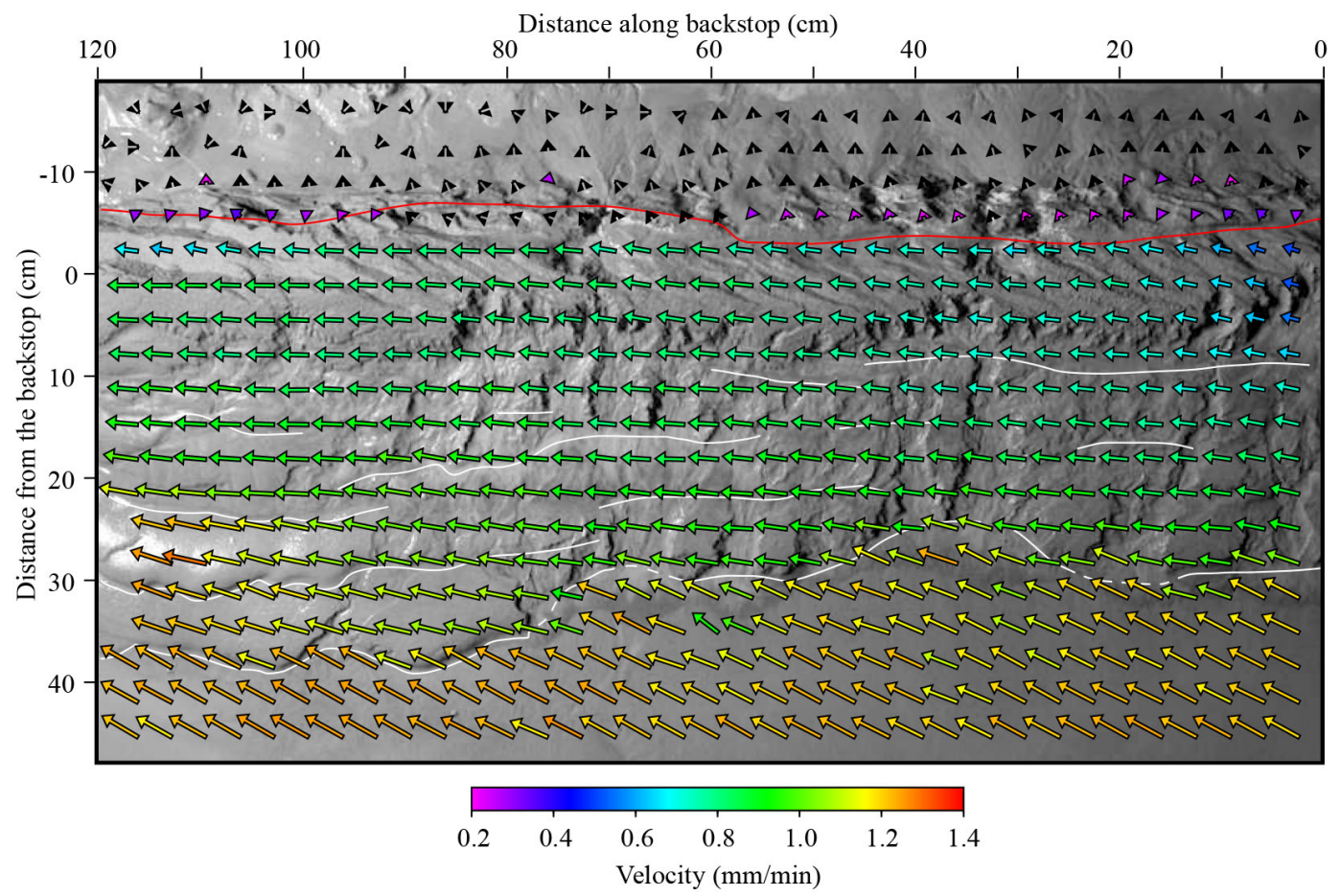

Figure 9: Typical velocity field map from image correlation between two pictures. The pro-shears are indicated in white and the main retro-shear in red. 

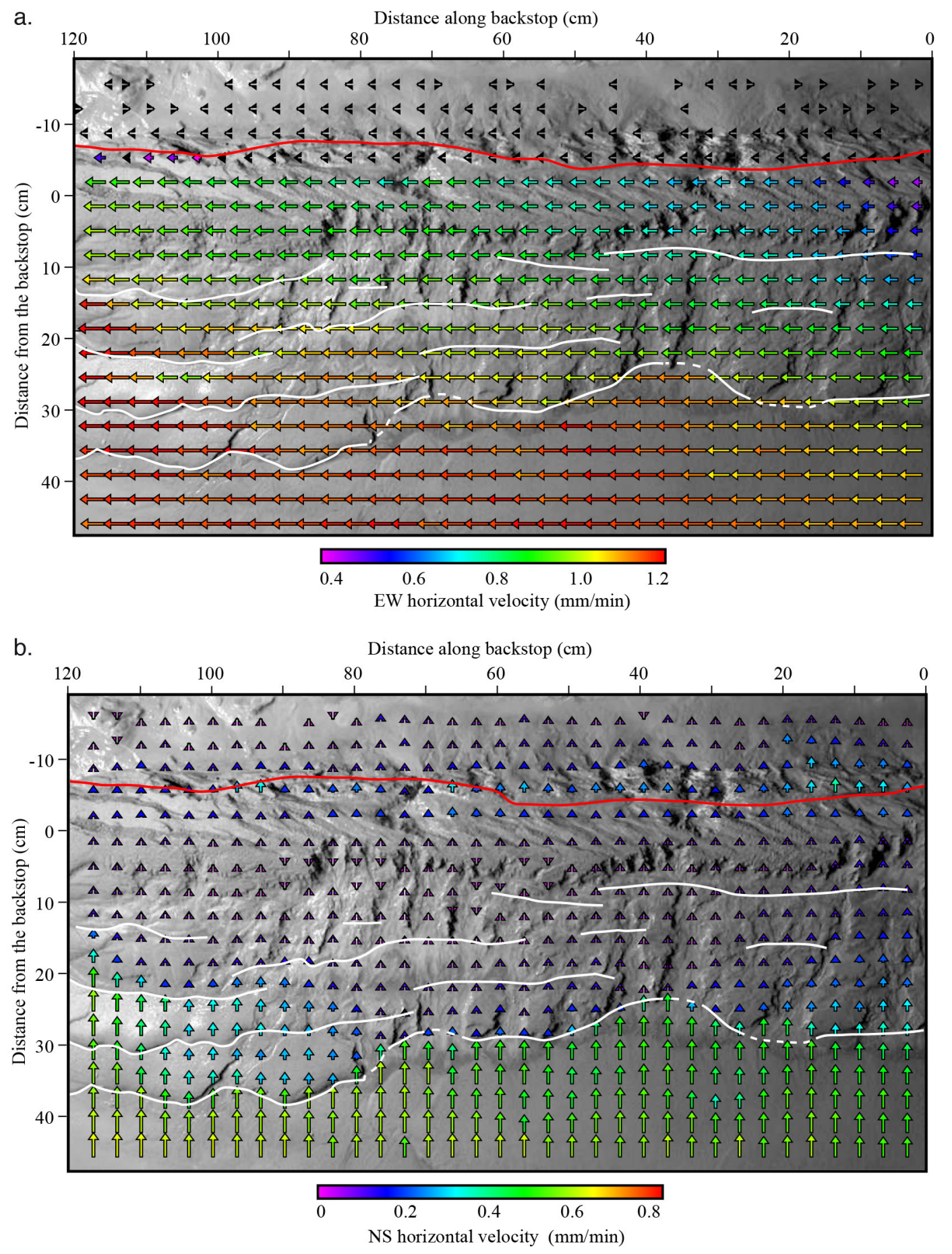

Figure 10: a) Fault-parallel (EW) and b) fault-perpendicular (NS) velocity field between two pictures. The pro-shears are indicated in white and the main retro-shear in red. 

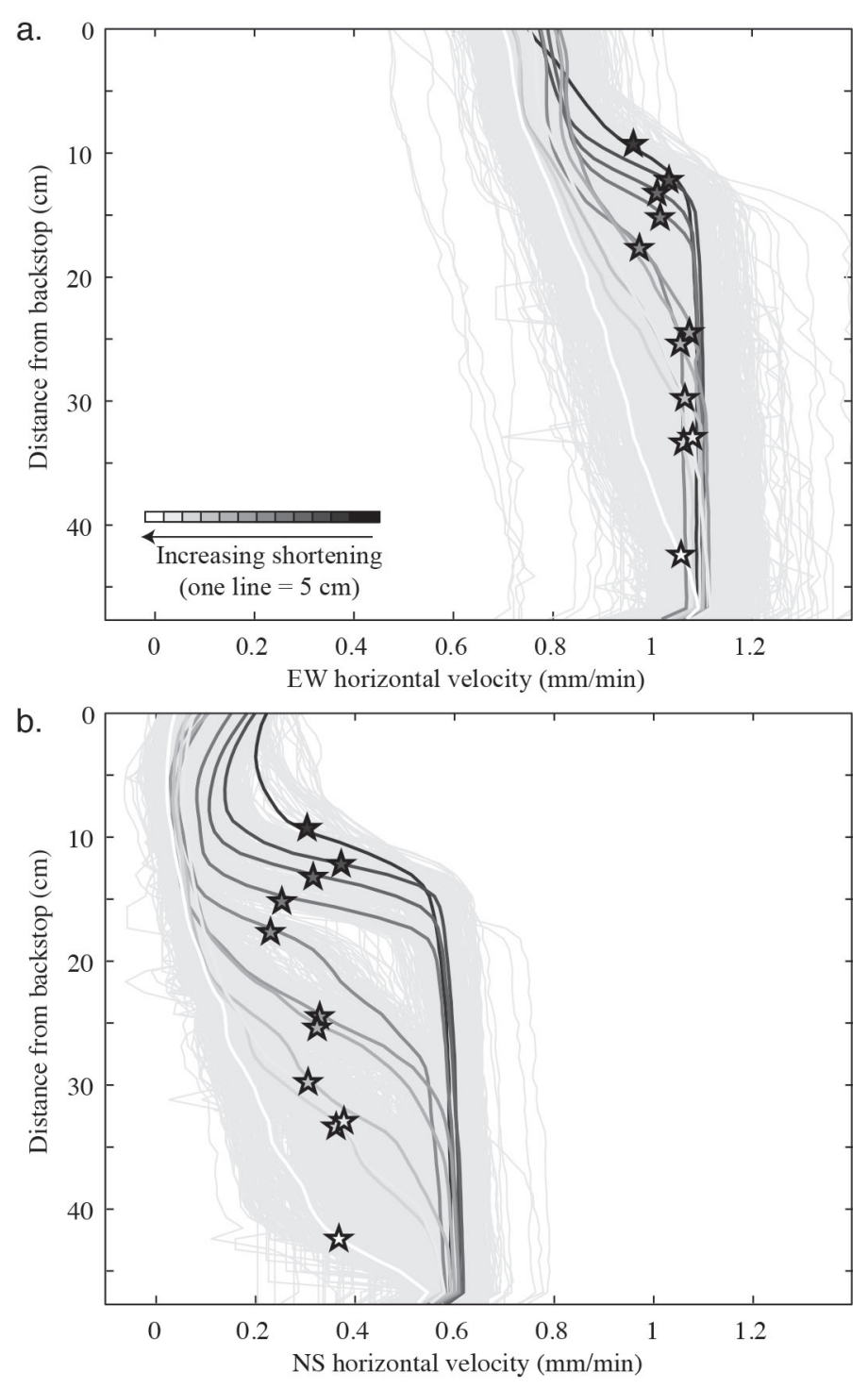

Figure 11: Average a) fault-parallel (EW) and b) fault-perpendicular (NS) velocity components across the wedge and in time. Light gray lines correspond to the velocity field for each picture, bold lines correspond to the average velocity field over $5 \mathrm{~cm}$ of shortening on which the average position of the wedge front during the corresponding time is indicated by a star. Distance is given from the position of the backstop at depth (S point). 

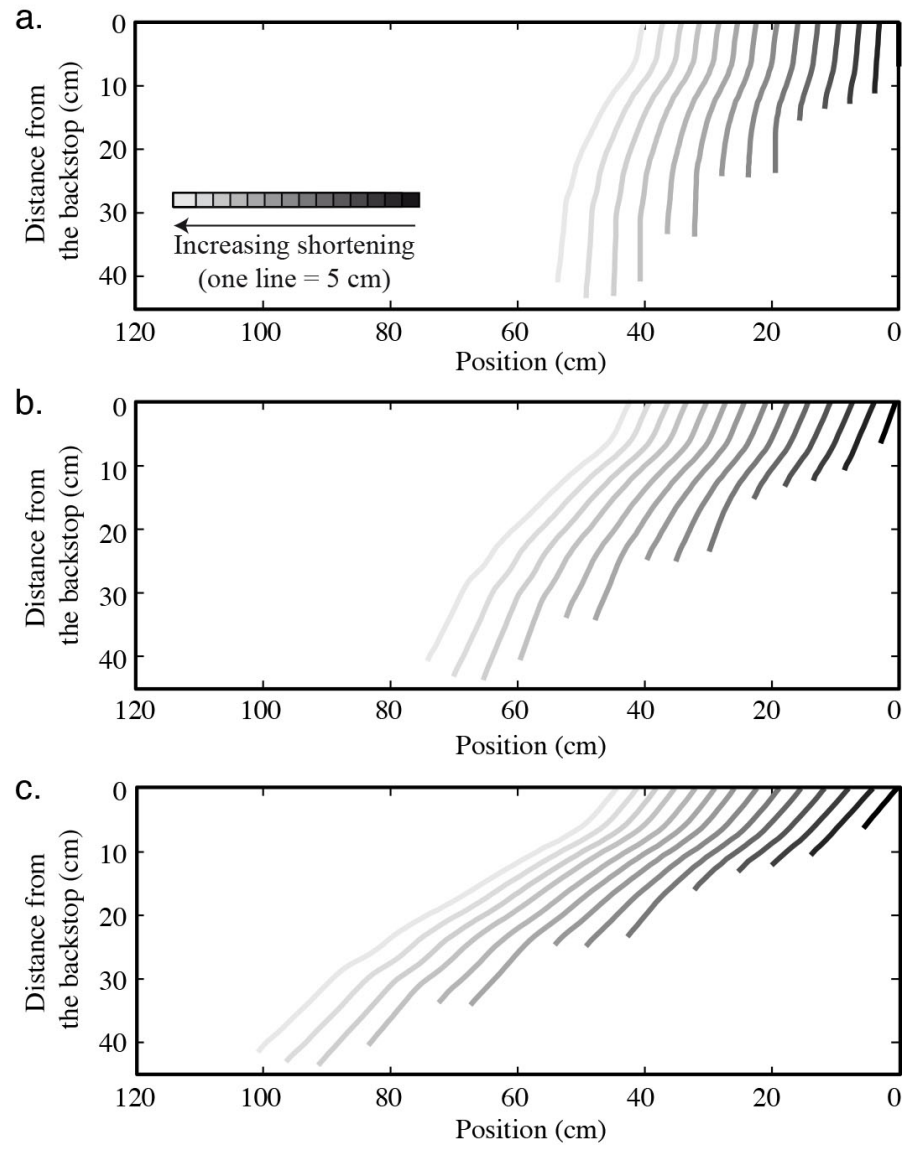

Figure 12: Rotation of a virtual passive marker due to imposed displacement during the whole duration of the experiment, with an initial orientation of a) $0^{\circ}$, b) $20^{\circ}$ and c) $40^{\circ}$ with respect to the North. Each line corresponds to an increment of $5 \mathrm{~cm}$ of total shortening. At each step, the length of the virtual marker is extended to the wedge front with the same initial orientation. 

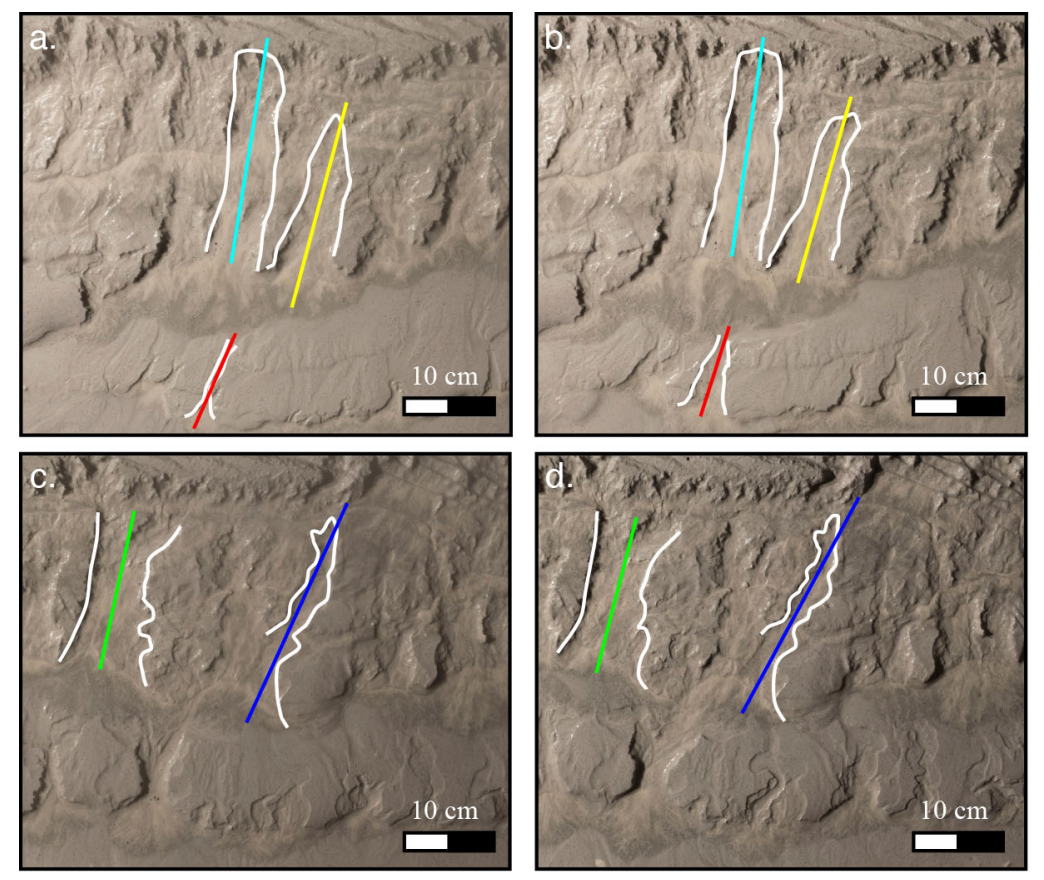

Figure 13: Examples of visually-defined orientation of a-b) three channels at $70 \mathrm{~cm}$ and $72.5 \mathrm{~cm}$ of shortening, respectively, and c-d) two channels at 75 and $77.5 \mathrm{~cm}$ of shortening, respectively. e) Average orientation with respect to the North of these five channels (circles) with respect to shortening, compared to the evolution expected for a virtual passive marker which would appear at the same moment, at the same position on the wedge surface and with the same initial orientation (dotted lines). 